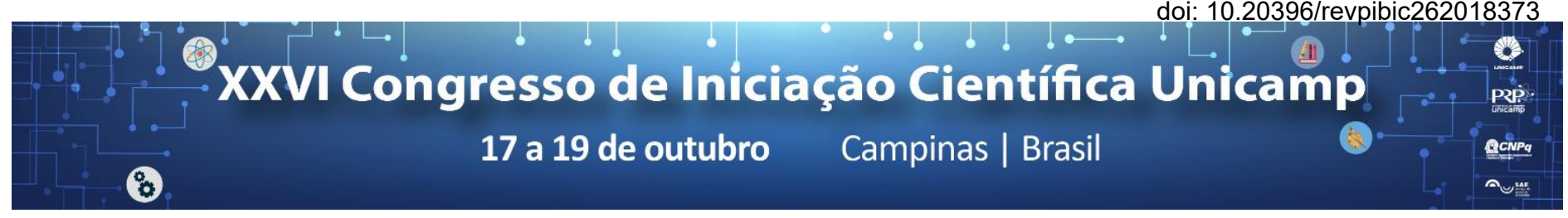

\title{
INVESTIGAÇÃO DOS LIMITES E POSSIBILIDADES DE ESTRATÉGIAS DE ENSINO UTILIZADAS NO CONTEXTO DE ATIVIDADES INTERDISCIPLINARES
}

\author{
Eduardo da Silva Machado*, Gildo Girotto Júnior
}

\begin{abstract}
Resumo
Diante da busca de estratégias de ensino baseado na proposta de interdisciplinaridade, a presente investigação almeja como resultados contribuir para o entendimento dos limites e possibilidades no desenvolvimento e aplicação de uma Sequência de Ensino Interdisciplinar (SEI), a partir dos estudos publicados e de ações desenvolvidas por profissionais e instituições de ensino. De forma específica, a presente revisão norteou-se na literatura referente às metodologias STEM education (ou STEAM) e Apredizagem Baseada em Problemas (ABP), de modo a encontrar conjunções entre essas propostas, buscando identificar também aspectos dentro das propostas que possibilitassem sua aplicação no contexto do ensino interdisciplinar. Por fim, diante do conhecimento teórico obtido da revisão bibliográfica, buscou-se entender os desafios, as vantagens, desvantagens, limitações e como as propostas interdisciplinares tem sido aplicadas em contextos reais por meio de entrevistas com professores de química do ensino médio que possibilitou correlacionar os fundamentos teóricos das metodologias aos cenários práticos apresentados pelos docentes entrevistados.
\end{abstract}

\section{Palavras-chave:}

Interdisciplinaridade; estratégias de ensino; sequências de ensino.

\section{Introdução}

A interdisciplinaridade (ID) pode ser entendida como uma condição fundamental do ensino e da pesquisa (em níveis universitários e do ensino médio) na sociedade contemporânea (LEIS, 2005). Frente a isso, verifica-se a importância, para a melhora dos resultados do ensino básico e superior, da busca pela compreensão de uma definição para o termo, bem como da investigação das maneiras de construir uma sequência de ensino interdisciplinar (SEI) e dos possíveis entraves existentes na aplicação e realização de uma proposta curricular baseada na ID.

O termo interdisciplinaridade, que inicialmente pode ser compreendido como um diálogo entre as disciplinas, na realidade deve ser considerado não apenas como tal, mas deve ser regido pela existência de uma finalidade comum às disciplinas envolvidas (JAPIASSU, 1976). É norteado por essa noção de ID que dentre as múltiplas propostas existentes para o ensino interdisciplinar, o presente trabalho procura discutir a proposta STEAM (sigla em inglês para ciências, tecnologia, engenharia, artes e matemática), como uma possibilidade para o ensino com foco na ID.

Além disso, o trabalho buscou encontrar na opinião de professores do ensino médio, os limites $e$ as possibilidades para o ensino interdisciplinar através de suas experiências com propostas desta natureza.

Resultados e Discussão

O contato entre a STEM Education e a ABP se concretiza quando tal imersão nos conhecimentos das quatros áreas se constrói a partir da proposição de um problema que traga como solução uma atitude norteada por princípios das quatro disciplinas de forma integrada, reiterando 0 caráter interdisciplinar que é norteador da STEM Education e da Aprendizagem Baseada em Problemas.

\section{Breve análise da pesquisa em interdisciplinaridade no Brasil}

Buscou-se nos trabalhos do "XI Encontro Nacional de Pesquisa em Ensino de Ciências - ENPEC" (o qual ocorreu em 2017) pesquisas que envolvam propostas, estratégias, metodologias de ensino para o trabalho interdisciplinar, de modo a obter uma revisão atualizada das pesquisas e práticas interdisciplinares.

Tabela 1. Classificação dos trabalhos sobre ID nos ENPECs

\begin{tabular}{|c|c|c|}
\hline Categoria de classificaçäo & $\begin{array}{c}\text { Lamego (2017)* - ENPECs } \\
\text { de 1997 a 2015 }\end{array}$ & Autores - XI ENPEC \\
\hline $\begin{array}{c}\text { Formação docente - inicial e } \\
\text { continuada / Concepções } \\
\text { sobre interdisciplinaridade - } \\
\text { estudantes e professores / } \\
\begin{array}{c}\text { Dificuldades na implantação } \\
\text { de práticas interdisciplinares }\end{array}\end{array}$ & 46 & 17 \\
\hline $\begin{array}{c}\text { Revisão Bibliogrâfica / } \\
\text { Abordagem epistemológica }\end{array}$ & 11 & 10 \\
\hline $\begin{array}{c}\text { Estratégias de ensino e } \\
\text { práticas para a }\end{array}$ & 25 & 9 \\
interdisciplinaridade & 25 & \\
\hline Adaptado pelos autores. & & \\
\hline
\end{tabular}

"Adaptado pelos autores.

\section{Conclusão}

Verificou-se a partir da leitura e análise dos documentos oficiais utilizados, bem como das entevistas com os professors de Ensino médio que é possível o trabalhe de forma interdisciplinar, assim como é possível construir uma SEI baseada no ensino integrado.

\section{Agradecimentos}

Agradeço a Deus pela oportunidade proporcionada. Família, amigos e orientador, fundamentais na concretização deste trabalho.

JAPIASSU, H. Interdisciplinaridade e patologia do saber. Rio de Janeiro: Imago, 1976

LAMEGO, C.R.S., Santos, M.C.F. Interdisciplinaridade e educação em ciências: uma pesquisa bibliográfica nos anais do i - x enpec (1997 - 2015). Anais do XI ENPEC, 2017.

LEIS, H.R. Sobre o conceito de interdisciplinaridade. Cadernos de pesquisa interdisciplinar em ciências humanas, v. 6, n. 73, p. 2-23, 2005. 